\title{
Parametric Optimization of Biodiesel Fuelled Engine Noise using the Taguchi Method
}

\author{
Satish A. Patil \\ Mechanical Engineering \\ Dr. D. Y. Patil Institute of Technology and \\ PDEA's College of Engineering \\ Pune, India \\ sapcoeh@rediffmail.com
}

\author{
R. R. Arakerimath \\ Mechanical Engineering \\ G H Raisoni College of Engineering and Management and \\ Savitribai Phule Pune University \\ Pune, India \\ rachayya.arakerimath@raisoni.net
}

\begin{abstract}
Biodiesel is a renewable, biodegradable, and efficient fuel that can be blended with petro-diesel in any proportion. The noise in the engine resulting from the combustion has a direct effect on the engine's performance. Many studies have examined the engines' vibration and noise when using diesel and biodiesel blends. This study examines the optimization of diesel blends, load, and compression ratio in the aspect of reducing noise on a Kirloskar single-cylinder diesel engine. Noise was measured at the engine and its exhaust on a computerized setup and for different loads. The experimental results showed that a blend with $15 \%$ biodiesel, at $7 \mathrm{~kg}$ load, and 18 compression ratio produced the lowest noise. Moreover, the Taguchi method was utilized, and experimental results were validated by an ANN.
\end{abstract}

\section{Keywords-transesterification; biodiesel; noise; optimization}

\section{INTRODUCTION}

Any alternative to diesel fuel should be replicable, economical, and technically acceptable [1]. Biodiesel is produced by the transesterification of renewable vegetable oils and animal fats with the use of alcohol. Biodiesel is highly degradable and nontoxic. Meanwhile, it has low emissions of carbon monoxide, particulate matter, and unburned hydrocarbons. Due to these properties, biodiesel has attracted wide attention as a replacement to diesel fuel $[1,2]$. Biodiesel can be used without modifications in conventional compression ignition engines. Noise and vibrations are major issues of diesel engines [3,4]. Engine body vibrations and noise are rich in information about the engine's operating parameters and physical condition $[4,5]$. Excess noise and vibrations wear out components such as bearings, grouting, and couplings, increasing maintenance cost due to more component failures and unplanned operations. Due to noise and vibrations' importance, there is a need to study the effect of biodiesel and its blends on engine's life and performance [6-8]. Noise level depends on the load and the blending ratio of biodiesel [5]. As a result, it is necessary to extend an engine's life by using optimal blends, after analyzing their impact in noise [5-9].

\section{EXPERIMENTAL PROCESS}

A Kirloskar TV1 VCR single cylinder, four stroke, constant speed, water-cooled diesel engine, having $3.5 \mathrm{HP}$ at $1500 \mathrm{rpm}$, was used on a computerized test bed equipped with measuring instruments such as thermocouples, dynamometer, tachometer and flow meters. The engine's specifications are shown in Table I.

TABLE I. ENGINE'S SPECIFICATIONS

\begin{tabular}{|c|c|}
\hline Name & Kirloskar \\
\hline No. of cylinders & 1 \\
\hline No. of strokes & 4 \\
\hline Type of cooling & Water cooled \\
\hline Power developing capacity & $3.5 \mathrm{~kW}$ at $1500 \mathrm{rpm}$ \\
\hline Compression ratio range & $12-18$ \\
\hline Stroke & $110 \mathrm{~mm}$ \\
\hline Bore & $87.5 \mathrm{~mm}$ \\
\hline Cylinder volume & 661 \\
\hline
\end{tabular}

Noise levels were measured by a noise meter for four different fuel blends on variable load conditions and compression ratios as per the Taguchi array. The study focused on the input parameters of biodiesel blends for examining the diesel engine's operating conditions. Noise was measured at the engine and its exhaust. A noise meter was placed at $0.5 \mathrm{~m}$ distance from the engine for measuring its noise, and another was placed outside the room near the exhaust pipe end to measure the noise at the exhaust [3-5]. The noise meter and its specifications are shown in Figure 1 and Table II respectively.

TABLE II. NOISE METER'S SPECIFICATIONS

\begin{tabular}{|c|c|}
\hline Display & $14 \mathrm{~mm}\left(0.55^{\prime \prime}\right)$ LCD with backlight \\
\hline Parameter measurement & $\mathrm{LP}, \mathrm{Lmax}, \mathrm{Leq}, \mathrm{LN}$ \\
\hline Frequency range & $31.5 \mathrm{~Hz} \sim 8 \mathrm{kHz}$ \\
\hline Measurement range & $\mathrm{LP}: 30 \sim 130 \mathrm{~dB}(\mathrm{~A})$ \\
\hline Resolution & $0.1 \mathrm{~dB}$ \\
\hline Accuracy & $\pm 1 \mathrm{~dB}$ \\
\hline
\end{tabular}

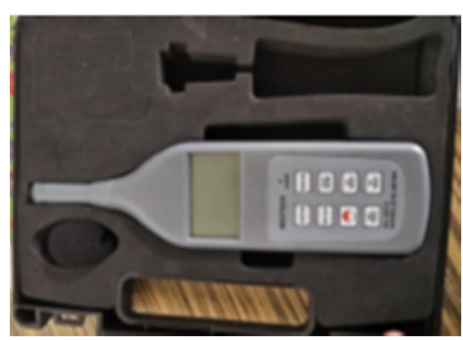

Fig. 1. Noise meter. 
Four fuel types were tested, namely: B0 consisting of $100 \%$ diesel, B15 consisting of $15 \%$ biodiesel and 85\% diesel, B20 consisting of $20 \%$ biodiesel and $80 \%$ diesel, and B25 consisting of $25 \%$ biodiesel and $75 \%$ diesel $[2,3,9]$. Biodiesel blend, load on the engine, and compression ratio were the parameters whose effects on the engine's noise were studied. The parameters' levels are listed in Table III.

TABLE III. PARAMETRIC CONDITIONS

\begin{tabular}{|c|c|c|}
\hline A: Blend & B: Load & C: Compression ratio \\
\hline $\mathrm{A} 1=0$ & $\mathrm{~B} 1=0$ & $\mathrm{C} 1=16$ \\
\hline $\mathrm{A} 2=15$ & $\mathrm{~B} 2=4$ & $\mathrm{C} 2=17$ \\
\hline $\mathrm{A} 3=20$ & $\mathrm{~B} 3=7$ & $\mathrm{C} 3=17.5$ \\
\hline $\mathrm{A} 4=25$ & $\mathrm{~B} 4=10$ & $\mathrm{C} 4=18$ \\
\hline
\end{tabular}

\section{A. Noise Analysis}

The orthogonal array of the input parameters indicates the number of combinations for the experiments. This selection of orthogonal array is based on three parameters and four levels for each parameter [2,5]. The array was obtained by Minitab using the following operating parameters:

Taguchi Design

Design Summary

Taguchi Array L16(4^3)

Factors: 3

Runs: 16

Columns of L16 (4^5) array: 123

TABLE IV. SAMPLE READINGS OF TAGUCHI ARRAY FOR PARAMETER OPTIMIZATION

\begin{tabular}{|c|c|c|c|c|c|c|}
\hline Blend & Load & C.R. & $\begin{array}{c}\text { Noise at } \\
\text { the engine }\end{array}$ & $\begin{array}{c}\text { Noise at } \\
\text { the } \\
\text { exhaust }\end{array}$ & $\begin{array}{c}\text { Noise at } \\
\text { the engine } \\
\text { SNR }\end{array}$ & $\begin{array}{c}\text { Noise at } \\
\text { the } \\
\text { exhaust } \\
\text { SNR }\end{array}$ \\
\hline 0 & 0 & 16 & 92.75 & 108.9 & -39.3463 & -40.7406 \\
\hline 0 & 4 & 17 & 93 & 109.25 & -39.3697 & -40.7684 \\
\hline 15 & 4 & 16 & 93.75 & 112.15 & -39.4394 & -40.996 \\
\hline 15 & 7 & 18 & 95 & 110.45 & -39.5545 & -40.8633 \\
\hline 15 & 10 & 17.5 & 95.6 & 110.95 & -39.6092 & -40.9025 \\
\hline 20 & 0 & 17.5 & 91.7 & 110.45 & -39.2474 & -40.8633 \\
\hline 25 & 10 & 16 & 96.35 & 111.9 & -39.677 & -40.9766 \\
\hline
\end{tabular}

The fourth row of Table IV gives the optimum values of input parameters for noise among the various blends. Signalto-noise ratio (SNR) measures how the response varies relatively to the nominal or target value under different noise conditions. Depending on the goal, different SNRs may be chosen. In this experiment, lower SNRs are better. Optimal conditions were met with B15 blend, $7 \mathrm{~kg}$ applied load, and 18 compression ratio, where the noise was $95 \mathrm{~dB}$ at the engine and $110.45 \mathrm{~dB}$ at the exhaust.

\section{B. Taguchi Analysis: Noise versus Blend, Load, C.R.}

Taguchi method analysis results for noise at the engine versus blend, load, and C.R are shown in Table V, while the regression's resulted equation is:

$$
\begin{gathered}
\text { Noise at the engine }=96.6-0.0507 \text { Blend } \\
+0.371 \text { Load }-0.255 C . R .
\end{gathered}
$$

TABLE V. NOISE AT THE ENGINE MODEL SUMMARY

\begin{tabular}{|c|c|c|}
\hline S & R-Sq & R-Sq(adj) \\
\hline 0.2196 & $76.30 \%$ & $40.76 \%$ \\
\hline
\end{tabular}

Taguchi model's analysis results on noise at the exhaust versus blend, load, and C.R are shown in Table VI, and the regression's resulted equation is:

$$
\begin{aligned}
& \text { Noise at the exhaust }=107.89+0.0518 \text { Blend } \\
& +0.1900 \text { Loads }+0.044 \text { C.R. }
\end{aligned}
$$

TABLE VI. NOISE AT THE EXHAUST MODEL SUMMARY

\begin{tabular}{|c|c|c|}
\hline S & R-Sq & R-Sq(adj) \\
\hline 0.0658 & $86.48 \%$ & $66.21 \%$ \\
\hline
\end{tabular}

\section{Validation of Experimental Results by Artificial Neural Network (ANN)}

The results of noise at the engine and the exhaust were validated by an ANN. An ANN script, shown in Table VII, was used for obtaining the output from the input parameters.

TABLE VII. ANN CONFIGURATION SCRIPT

\begin{tabular}{|l|}
\hline clc; close all; clear all; \\
\hline $\mathrm{x}=$ xlsread('Input1'); \\
\hline $\mathrm{y}=$ xlsread('Output2'); \\
\hline net = newff(minmax(x),[20,1],\{'logsig','purelin','trainlm' $\}) ;$ \\
\hline net.trainparam.epochs = 1000; \\
\hline net.trainparam.goal =1e-15; net.trainparam.lr = 0.01; \\
\hline net = train(net, $x, y) ;$ \\
\hline y_net = net(x); \\
\hline plot(y);hold on; plot(y_net, 'r'); \\
\hline error =(y - y_net); \\
\hline
\end{tabular}

\section{RESULTS AND VALIDATION}

\section{A. Noise at the Engine}

The experimental results for noise at the engine, the values calculated by the ANN, and the error between them are shown in Table VIII and a comparative graph of these values is shown in Figure 2. Apparently, there is a small difference, less than $1.2 \%$, between the experimental and the ANN calculated values.

TABLE VIII. EXPERIMENTAL AND ANN RESULTS

\begin{tabular}{|c|c|c|c|c|c|c|}
\hline Blend & Load & C.R. & $\begin{array}{c}\text { Noise at the } \\
\text { engine }\end{array}$ & $\begin{array}{c}\text { Noise by } \\
\text { ANN }\end{array}$ & Error & Error \% \\
\hline 0 & 7 & 17.5 & 97 & 96 & -1 & $-1.0 \%$ \\
\hline 0 & 10 & 18 & 95.2 & 96 & 0.8 & $0.8 \%$ \\
\hline 15 & 7 & 18 & 95 & 96 & 1 & $1.0 \%$ \\
\hline 20 & 10 & 17 & 95.9 & 95.5 & 0 & $0.0 \%$ \\
\hline 25 & 7 & 17 & 94.8 & 95.6 & 0.8 & $0.8 \%$ \\
\hline 25 & 10 & 16 & 96.35 & 95.2 & -1.15 & $-1.2 \%$ \\
\hline
\end{tabular}

The regression plot obtained by the Taguchi model for the experimental results was compared with the ANN regression plot. The regressions' R-square value was around $80 \%$. The straight line in these plots shows that the data fit a normal probability distribution. There are very low residual values, as 
all residuals obtained are almost along the line in both plots. The similarity in these plots validates the results.

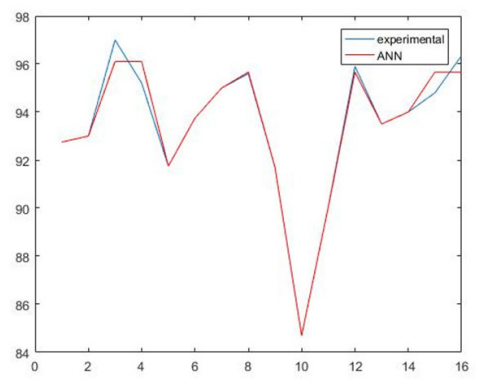

Fig. 2. Comparison of experimental and ANN noise values at the engine.

(a)

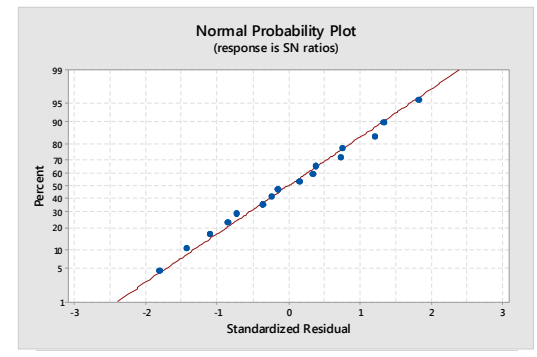

(b)

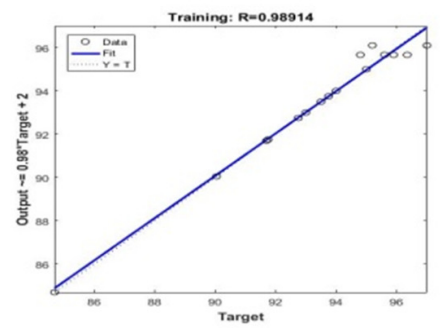

Fig. 3. Residual plot for noise at the engine by (a) Minitab, (b) ANN.

\section{B. Noise at the Exhaust}

The experimental results of noise at the exhaust, the values calculated by the ANN, and the error between them are given in Table IX. Moreover, a comparative graph of these values is shown in Figure 4. Apparently, there is a tiny difference between experimental and ANN results, less than $0.3 \%$, for noise at the exhaust.

TABLE IX. EXPERIMENTAL AND ANN RESULTS

\begin{tabular}{|c|c|c|c|c|c|c|}
\hline Blend & Load & C.R. & Noise at the exhaust & Noise byANN & Error & Error \% \\
\hline 0 & 0 & 16 & 108.9 & 109.2 & 0.3 & $0.27 \%$ \\
\hline 0 & 4 & 17 & 109.25 & 109.1 & -0.15 & $-0.14 \%$ \\
\hline 15 & 7 & 18 & 110.45 & 110.45 & 0 & $0.00 \%$ \\
\hline 15 & 10 & 17.5 & 110.95 & 110.95 & 0 & $0.00 \%$ \\
\hline 20 & 0 & 17.5 & 110.45 & 110.45 & 0 & $0.00 \%$ \\
\hline 25 & 10 & 16 & 111.9 & 111.9 & 0 & $0.00 \%$ \\
\hline
\end{tabular}

After comparing the regression plots of experimental and ANN results in Figures 3 and 5, we can see that there are very few residual values, and all values obtained are almost along the line indicating a normal probability distribution. The regression's R-square value was $86.48 \%$. The similarity in these plots validates the results.

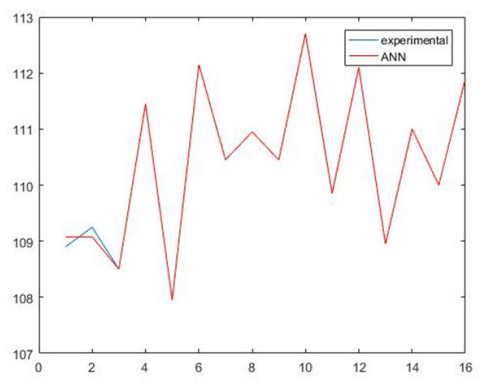

Fig. 4. Comparison of experimental and ANN noise at exhaust.

(a)

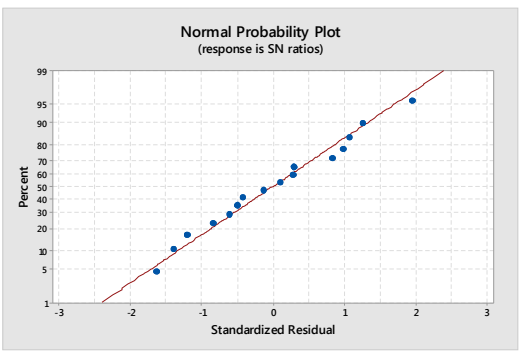

(b)

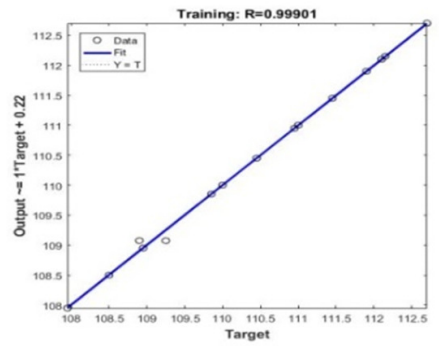

Fig. 5. Residual plot for noise at the exhaust by (a) Minitab, (b) ANN.

\section{CONCLUSION}

This study examined the optimization of noise reduction at the engine and its exhaust with biodiesel blend, load, and compression ratio of the engine as input parameters. Analysis was carried out utilizing the Taguchi method, and optimization of the input parameters was performed by using SNR $[10,11]$. The experimental results obtained by Minitab were validated by an ANN. The main conclusions of this study are:

- Optimal input parameters were: a blend with $15 \%$ biodiesel, applied load of $7 \mathrm{~kg}$, and compression ratio 18 , resulting to $95 \mathrm{~dB}$ noise at the engine and $110.45 \mathrm{~dB}$ at its exhaust.

- R-square values obtained by regression analysis were around $80 \%$ and more, indicating that the obtained model fits to the actual data.

- There are small to tiny differences between the experimental and the ANN's noise values.

- All regression residuals of both Minitab and ANN were very low and almost along the line in both methods. The similarities in both plots validated the results. 


\section{REFERENCES}

[1] D. Patil and R. Arakerimath, "Performance characteristics and analysis of Jatropha oil in multi-cylinder turbocharge Compression Ignition Engine," International Journal of Engineering Research and Development, vol. 1, no. 10, pp. 50-55, Jun. 2012.

[2] S. A. Patil and R. R. Arakerimath, "Optimization of Biodiesel Synthesis using Heterogeneous Catalyst (SiO2) from Karanja Oil by Taguchi Method," International Journal of Engineering and Advanced Technology, vol. 9, no. 2, pp. 5597-5600, Dec. 2019.

[3] A. A. Khaskheli, H. J. Arain, I. A. Memon, U. A. Rajput, and M. J. Ahsan, "Emission and Noise Characteristics of a Diesel Engine Fuelled with Diesel-Chicken Oil Biodiesel Blends," Engineering, Technology \& Applied Science Research, vol. 10, no. 2, pp. 5387-5391, Apr. 2020.

[4] S. Saridemir and U. Agbulut, "Combustion, performance, vibration and noise characteristics of cottonseed methyl ester-diesel blends fuelled engine," Biofuels, Sep. 2019, doi: 10.1080/17597269.2019.1667658.

[5] E. Uludamar, E. Tosun, and K. Aydın, "Experimental and regression analysis of noise and vibration of a compression ignition engine fuelled with various biodiesels," Fuel, vol. 177, pp. 326-333, Aug. 2016, doi: 10.1016/j.fuel.2016.03.028.

[6] H. Yildırım, A. N. Özsezen, and A. Cinar, "Vibration and Noise Depending upon Engine Speed in aDiesel Engine Fueled with Biodiesel," presented at the 6th European Conference on Renewable Energy Systems, Istanbul, Turkey, Jun. 25-27, 2018.

[7] B. Heidary, S. R. Hassan-beygi, B. Ghobadian, and A. Taghizadeh, "Vibration analysis of a small diesel engine using diesel-biodiesel fuel blends," Agricultural Engineering International: CIGR Journal, vol. 15, no. 3, pp. 117-126, Jul. 2013.

[8] J. A. Grajales, H. F. Quintero, C. A. Romero, and E. Henao, "Engine Diagnosis Based on Vibration Analysis Using Different Fuel Blends SpringerLink," Advances in Condition Monitoring of Machinery in NonStationary Operations, vol. 9, pp. 267-274, Sep. 2017.

[9] K. Sivaramakrishnan and P. Ravikumar, "Performance Optimization of Karanja Biodiesel Engine Using Taguchi Approach and Multiple Regresssions," ARPN Journal of Engineering and Applied Sciences, vol. 7, no. 4, pp. 506-516, Apr. 2012.

[10] S. Jaikumar, S. K. Bhatti, and V. Srinivas, "Emission and vibration characteristics of Niger seed oil biodiesel fueled diesel engine," Journal of Mechanical Engineering and Sciences, vol. 13, no. 4, pp. 5862-5874, Dec. 2019, doi: 10.15282/jmes. 13.4.2019.11.0467.

[11] M. M. Ettefagh, M. H. Sadeghi, V. Pirouzpanah, and H. Arjmandi Tash, "Knock detection in spark ignition engines by vibration analysis of cylinder block: A parametric modeling approach," Mechanical Systems and Signal Processing, vol. 22, no. 6, pp. 1495-1514, Aug. 2008, doi: 10.1016/j.ymssp.2007.11.027.

\section{AUTHORS PROFILE}

Satish A. Patil is a research Scholar at the Mechanical Engineering, Dr. D. Y. Patil Institute of Technology (DYPIT), Pune (MS), India, and a Assistant Professor in the Department of Mechanical Engineering, PDEAs College of Engineering, Manjari (Bk), Pune, India. Affiliated to Savitribai Phule Pune University, Pune.

Rachayya R. Arakerimath is a Professor and the Head of the Mechanical Engineering Department, Savitribai Phule Pune University, Pune G H Raisoni College of Engineering, Pune, India. He has 24 years of teaching experience and has worked at various levels. He is an approved Ph.D. guide under the Universities of Pune and Nagpur. He has published more than 100 papers in conferences and journals. He is also a reviewer for international journals. 